\title{
SUPRESSÃO DE PLANTAS DANINHAS E PRODUÇÃO DE SEMENTES DE CROTÁLARIA, EM FUNÇÃO DE MÉTODOS DE SEMEADURA ${ }^{1}$
}

\author{
Paulo César Timossi ${ }^{2}$, Carolina Wisintainer ${ }^{3}$, \\ Bruce James dos Santos ${ }^{4}$, Vinícius André Pereira ${ }^{4}$, Vladimir Sperandio Porto ${ }^{4}$
}

\section{ABSTRACT \\ WEEDS SUPPRESSION AND Crotalaria juncea $\mathrm{L}$. SEEDS YIELD UNDER DIFFERENT SOWING METHODS}

Green fertilizers can promote a significant weeds control, due to their fast growth rate, increasing the interespecific competition, mainly for space. This study aimed to evaluate the intercropping Crotalaria juncea L. sowing methods on weeds suppression and seeds yield. The experimental design was randomized blocks, with four treatments (sowing at $0.50 \mathrm{~m}$ and $0.75 \mathrm{~m}$ between rows, haul, and control) and three replications. At 50 days after sowing (DAS), the weeds density and specific composition were determined. For determining dry mass, weeds and Crotalaria juncea were collected at 100 DAS, while, at 200 DAS, only weeds were collected. Then, the data were submitted to variance analysis and means compared by using the Tukey test, at $5 \%$. It was possible to conclude that the presence of Crotalaria juncea inhibited the development of the weeds community, with no differences among treatments. The same occurred for seeds yield.

KEY-WORDS: Crotalaria juncea L.; crop control; green fertilizers; crop succession.

\section{INTRODUÇÃO}

Adubação verde consiste no plantio de uma espécie vegetal, que, após atingir seu pleno desenvolvimento vegetativo, será incorporada ou acamada. A massa deixada sobre a superfície, ou incorporada ao solo, com a finalidade de se manter ou aumentar o seu conteúdo de matéria orgânica, é capaz de melhorar as qualidades físicas, químicas e biológicas do solo, favorecendo o crescimento e o rendimento de culturas em sucessão (Souza \& Pires 2002).

Dentre as plantas utilizadas para a adubação verde, as leguminosas são as mais difundidas, por

\section{RESUMO}

Espécies de adubos verdes podem suprimir significativamente a infestação de plantas daninhas, por apresentarem crescimento rápido, aumentando a competição interespecífica, principalmente por espaço. Objetivou-se, com esta pesquisa, avaliar métodos de semeadura de Crotalaria juncea L., cultivada na entressafra, sobre a supressão de plantas daninhas e produção de sementes. Adotou-se o delineamento experimental em blocos ao acaso, com quatro tratamentos (semeadura no espaçamento entre linhas de $0,50 \mathrm{~m}$ e $0,75 \mathrm{~m}$ e a lanço e área sem semeadura pousio) e três repetições. Aos 50 dias após a semeadura (DAS), foi determinada a densidade e composição específica de plantas daninhas. Para a determinação de massa seca, foram feitas coletas, aos 100 DAS, de plantas daninhas e crotalária e, aos 200 DAS, apenas de plantas daninhas. Os dados obtidos foram submetidos a análise de variância e as médias comparadas pelo teste Tukey, a 5\%. Pôde-se concluir que a presença da crotalária suprimiu o desenvolvimento da comunidade de plantas daninhas, sem apresentar diferenças entre os tratamentos propostos. O mesmo aconteceu com a produtividade de sementes.

PALAVRAS-CHAVE: Crotalaria juncea L.; controle cultural; adubos verdes; sucessão de culturas.

apresentarem, em geral, sistema radicular profundo e ramificado, com capacidade de fixar nitrogênio atmosférico, mediante a simbiose com bactérias do gênero Rhizobium (Dourado et al. 2001), favorecendo culturas em sucessão.

Segundo Amabile et al. (2000), dentre as diversas leguminosas promissoras à adubação verde, na região dos Cerrados, destacam-se a mucuna-preta [Mucuna aterrima (Piper e Tracy) Merr.], guandu [Cajanus cajan (L.) Millsp], crotalárias (Crotalaria juncea L., C. ochroleuca G. Dom, C. paulina Schrank e C. spectabilis Roth), feijão-bravo-do-Ceará (Canavalia brasiliensis Mart e Benth), feijão-de-

1. Trabalho recebido em set./2010 e aceito para publicação em ago./2011 (n registro: PAT 11603/ DOI: 10.5216/pat.v41i4.11603).

2. Universidade Federal de Goiás, Unidade Jatobá, Jataí, GO, Brasil.E-mail: ptimossi2004@yahoo.com.br.

3. Universidade Federal de Goiás, Escola de Agronomia e Engenharia de Alimentos, Goiânia, GO, Brasil.

E-mail: carolinawisintainer@hotmail.com.

4. Universidade Estadual de Goiás, Unidade Universitária de Ipameri, Ipameri, GO, Brasil.

E-mails: brucejs@gmail.com, fidubil@hotmail.com,vado.sperandio@hotmail.com. 
-porco [Canavalia ensiformis (L.) DC.] e estilosantes (Stylosanthes sp. Sw.).

A adoção da adubação verde também pode interferir no manejo integrado de plantas daninhas (MIPD), suprimindo reinfestações, além de diminuir o banco de sementes. Para Favero et al. (2001), Sodré Filho et al. (2004) e Monqueiro et al. (2009), a adubação verde pode provocar modificações na população de plantas daninhas, devido aos efeitos alelopáticos e competição por luz, água, oxigênio e nutrientes, acarretando a supressão de algumas delas.

Severino \& Christoffoleti (2001), estudando a composição do banco de sementes de plantas daninhas, em solos cultivados com adubos verdes, verificaram que a Crotalaria juncea promoveu maior controle sobre a vegetação espontânea do que outras espécies de adubos verdes, reduzindo, significativamente, a infestação de plantas daninhas.

Cava et al. (2008), avaliando o potencial de supressão de plantas daninhas pelos adubos verdes Crotalariajuncea, Crotalaria spectabilis e Canavalia ensiformis, constataram que o mais eficiente foi C. juncea, por apresentar rápido crescimento, aumentando a competição, principalmente por luz.

Em regiões onde o regime hídrico não pos-sibilita o cultivo de $2^{\mathrm{a}}$ safra, a semeadura da Crotalaria juncea, após a colheita da cultura principal, pode ser uma alternativa ao pequeno produtor, pois, além de suprimir a reinfestação de plantas daninhas, para o próximo ano agrícola, proporciona renda extra, com a produção de sementes. A comercialização das mesmas tem se tornado interessante, pois o setor canavieiro tem absorvido grande parte do volume produzido, visando à adoção do cultivo em áreas de renovação de canaviais, onde há curto espaço de tempo entre cultivos de cana-de-açúcar. Entretanto, quanto à produção de sementes desta espécie, estudos são escassos. Ainda, de acordo com Aguiar et al. (2008), espécies de adubos verdes também são adotadas em sistemas de cultivo orgânico, consolidando a premissa da necessidade de estudos, quanto à produção de sementes desta espécie.

O objetivo deste trabalho foi avaliar a supressão de plantas daninhas e a produção de sementes de Crotalariajuncea, sob diferentes métodos de semeadura.

\section{MATERIAL E MÉTODOS}

O experimento foi instalado em área de pesquisa da Universidade Estadual de Goiás, Unidade de Ipameri, entre fevereiro e julho de 2008. O solo da área experimental foi classificado como Latossolo Vermelho-Amarelo eutrófico (LVAe), fase Cerrado, muito profundo e com relevo suave ondulado, cujo resultado da análise de fertilidade indicou os seguintes valores: $\mathrm{pH}\left(\mathrm{H}_{2} \mathrm{O}\right): 6,3 ; \mathrm{P}: 2,2 \mathrm{mg} \mathrm{dm}^{-3}$; $\mathrm{K}: 62,0 \mathrm{mg} \mathrm{dm}^{-3} ; \mathrm{Ca}: 4,2 \mathrm{cmol}_{\mathrm{c}} \mathrm{dm}^{-3} ; \mathrm{Mg}: 1,0 \mathrm{cmol}_{\mathrm{c}} \mathrm{dm}^{-3}$; Al: $0,0 \mathrm{cmol}_{\mathrm{c}} \mathrm{dm}^{-3} ; \mathrm{H}+\mathrm{Al}: 2,1 \mathrm{cmol}_{\mathrm{c}} \mathrm{dm}^{-3} ; \mathrm{m}: 0,0 \%$; V: $63 \%$; C.O.: $21,0 \mathrm{~g} \mathrm{dm}^{-3}$; Cu: $1,2 \mathrm{mg} \mathrm{dm}^{-3}$; Fe: $42,0 \mathrm{mg} \mathrm{dm}^{-3}$; Mn: 14,2 $\mathrm{mg} \mathrm{dm}^{-3}$; e Zn: 3,4 $\mathrm{mg} \mathrm{dm}^{-3}$.

$\mathrm{O}$ delineamento experimental adotado foi o de blocos ao acaso, com quatro tratamentos e três repetições. Os tratamentos foram constituídos de Crotalaria juncea, em diferentes métodos de semeadura ( $0,50 \mathrm{~m}, 0,75 \mathrm{~m}$ e a lanço), além de testemunha sem cultivo, para estudar a composição específica de plantas daninhas e o máximo acúmulo de massa seca das mesmas (pousio). A área de cada parcela foi de $6 \mathrm{~m} \mathrm{x} 4 \mathrm{~m}$, totalizando $24 \mathrm{~m}^{2}$. Quanto à densidade das sementes, foi adotado o valor de $30 \mathrm{~kg} \mathrm{ha}^{-1}$, para todos os tratamentos, com semeadura realizada em 19/02/2008, sob o sistema convencional. Para estabelecer os métodos de semeadura, adotou-se a abertura de sulcos (com o uso de enxadas), para a semeadura em linhas, e, para a semeadura a lanço, realizou-se incorporação superficial das sementes, com o uso de "rastelo de dentes". Não foram realizados tratos culturais na espécie vegetal, com o objetivo de se avaliar o potencial de produção de sementes da mesma, em situações de reciclagem de nutrientes.

As avaliações basearam-se na determinação da composição específica e acúmulo de massa seca de plantas daninhas, além da produtividade de sementes de crotalária. Aos 50 dias após a semeadura (DAS), foi determinada a densidade e a composição específica de plantas daninhas. Para isto, lançou-se, ao acaso, duas vezes por parcela, quadro metálico de $0,5 \mathrm{~m}^{2}$, totalizando $1 \mathrm{~m}^{2}$ amostrado. Para a determinação de massa seca, foram feitas coletas, aos $100 \mathrm{DAS}$, tanto de plantas daninhas quanto de crotalária, e, aos 200 DAS, apenas de plantas daninhas, adotando-se o mesmo procedimento. As amostras foram acondicionadas em sacos de papel e secas em câmara de circulação forçada de ar, a $70^{\circ} \mathrm{C}$, por 72 horas.

Para determinação do potencial produtivo da espécie de crotalária, aos 200 DAS, foram colhidas e debulhadas, manualmente, as vagens, para obtenção da massa de sementes presentes na área útil $\left(9 \mathrm{~m}^{2}\right)$ das 
parcelas. A umidade das sementes foi determinada com o auxílio da seguinte fórmula: $\%$ Umidade $=$ $[$ (massa úmida - massa seca)/(massa úmida) $] * 100$.

Para a determinação da massa seca das sementes, foi adotada a permanência das mesmas, por 24 horas, em estufa, a $104,5^{\circ} \mathrm{C}$. Para fins de padronização e determinação de produtividade, a umidade das sementes foi corrigida para $7 \%$.

Os dados de precipitação pluviométrica, referentes ao período de condução da pesquisa, foram obtidos na Estação Agroclimatológica pertencente ao Instituto Nacional de Meteorologia (INMET), localizada a $3 \mathrm{~km}$ da área experimental. $\mathrm{O}$ acúmulo mensal da precipitação $(\mathrm{mm})$ é apresentado na Figura 1. Quando necessário, os dados obtidos foram submetidos a análise de variância e as médias comparadas pelo teste Tukey, a 5\%.

\section{RESULTADOS E DISCUSSÃO}

As principais espécies de plantas daninhas obtidas na determinação da composição específica foram: Digitaria horizontalis (capim-colchão), com 69,5\%; Chamaesyce hirta (erva-de-Santa-Luzia), com 13,1\%; Brachiaria ruziziensis (braquiária ruziziensis), com 5,2\%; Emilia fosbergii (falsa-serralha), com 3,7\%; Acanthospermum australe (carrapicho-rasteiro), com 3,4\%; e Eleuzine indica (capim-pé-de-galinha), com 2,1\%. Ainda, compondo a comunidade infestante, porém com representatividade abaixo de $1 \%$, fizeram-se presentes as seguintes espécies: Commelina benghalensis (trapoeraba), Tridax procumbens (erva-de-touro), Portulaca oleracea (beldroega), Sida sp. (guanxuma), Raphanus sativus (nabiça) e Euphorbia heterophylla (leiteiro).

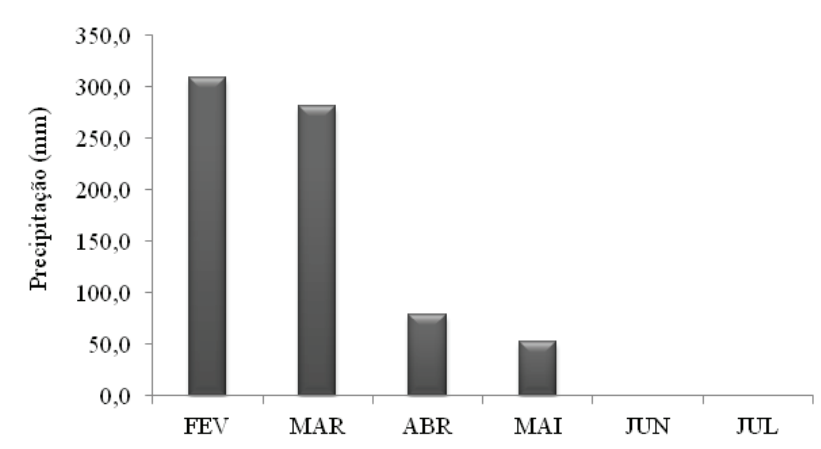

Figura 1. Precipitação pluviométrica mensal obtida durante a condução da pesquisa no campo (Ipameri, GO, 2008).
A densidade de plantas daninhas, avaliada aos 50 dias após a semeadura (DAS) da crotalária, não diferiu entre os tratamentos (Figura 2). Neste período (50 DAS), as plantas de crotalária, independentemente de sua distribuição, não interferiram na emergência de plantas daninhas. Isto ocorreu devido ao pequeno porte das plantas de crotalária, o qual tornou-as incapazes de suprimir a emergência de plantas daninhas. Trabalhos como o de Erasmo et al. (2004) e Monqueiro et al. (2009) mencionam o potencial alelopático de C. juncea sobre a comunidade de plantas daninhas. Teixeira et al. (2004), estudando extratos aquosos de adubos verdes na germinação e índice de velocidade de germinação (IVG) de Bidens pilosa, também verificaram reduções de até $35,5 \%$ na germinação. No entanto, nesta pesquisa, pôde-se constatar que o efeito supressivo sobre as plantas daninhas só ocorreu a partir dos $50 \mathrm{DAS}$, culminando com o crescimento acentuado das plantas de crotalária.

Nas médias de acúmulo de massa seca $\left(\mathrm{kg} \mathrm{ha}^{-1}\right)$ de plantas daninhas determinadas aos 100 DAS, pôde-se constatar que a presença da crotalária inibiu o desenvolvimento da comunidade de plantas daninhas, sem, no entanto, haver diferenças entre as formas de semeadura (Figura 3).

A utilização de culturas sucessoras tem sido uma forma interessante de manejo de plantas daninhas. No planejamento de cultivo, a manutenção de adubos verdes interfere diretamente na competição por luz e espaço, diminuindo a probabilidade de perpetuação de algumas espécies daninhas de difícil controle (Sodré Filho et al. 2004, Cava et al. 2008). Especula-se que, além do estabelecimento da competição, pode ter ocorrido ação alelopática, por parte da C. juncea. Monqueiro et al. (2009), estudando o efeito supressor de diferentes espécies de adubos

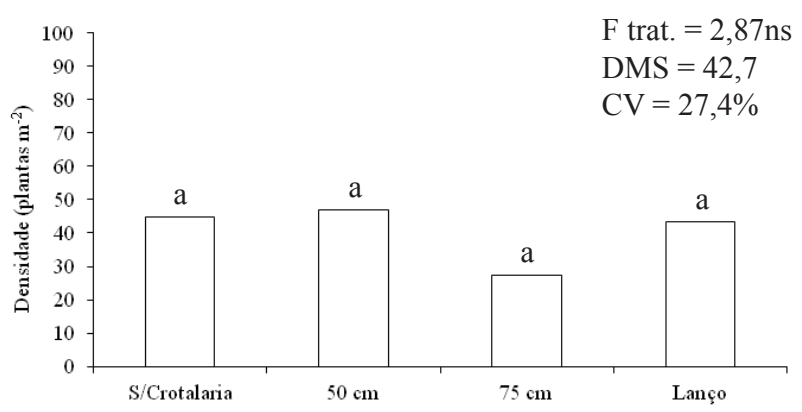

Figura 2. Densidade de plantas daninhas (número de plantas $\mathrm{m}^{-2}$ ), aos 50 dias após a semeadura de Crotalaria juncea, em função de métodos de semeadura (Ipameri, GO, 2008). 


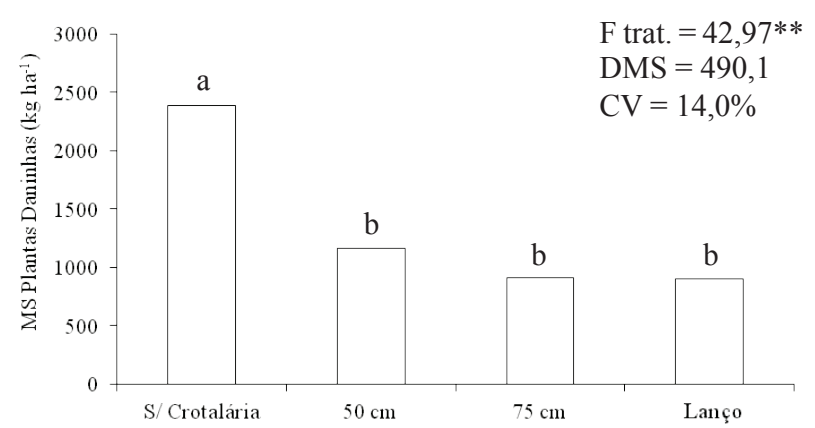

Figura 3. Acúmulo de massa seca $\left(\mathrm{kg} \mathrm{ha}^{-1}\right)$ de plantas daninhas no cultivo de Crotalaria juncea, sob diferentes métodos de semeadura, aos 100 dias após a semeadura (Ipameri, GO, 2008).

verdes, verificaram que as gramíneas Brachiaria decumbens e Panicum maximum foram suprimidas pela $C$. juncea. O mesmo foi constatado por Erasmo et al. (2004), estudando o potencial supressor de diversas espécies de adubos verdes, no qual verificaram redução significativa na população e massa seca de Digitaria horizontalis, Hyptis lophanta e Amaranthus spinosus.

Aos 200 DAS, verificou-se a mesma tendência, com semelhança na supressão da infestação por planta daninha na área, embora com intensa diminuição no acúmulo de massa seca obtida pela comunidade infestante (Figura 4), quando comparada à avaliação anterior (100 DAS). Isto foi observado devido à senescência de espécies de ciclo de vida anual, como, principalmente, a de capim-colchão. Desta forma, pode-se afirmar que a presença de cultura sucessora auxilia na supressão de plantas daninhas, corroborando as afirmações de Severino \& Christoffoleti (2001).

Nas médias de acúmulo de massa seca $\left(\mathrm{kg} \mathrm{ha}^{-1}\right)$ de plantas de C. juncea, pôde-se verificar que não houve diferenças entre os métodos adotados (Figura 5).

Esta característica pode ter sido o ponto crucial para a obtenção de supressão semelhante, quanto ao acúmulo de massa seca, pelas plantas daninhas. É provável que as condições climáticas da região tenham interferido nesta característica, pois o período de cultivo da crotalária culminou com o início da estação seca, ocorrendo déficit hídrico ao longo do desenvolvimento da mesma. Cava et al. (2008) obtiveram 14,5 $\mathrm{t} \mathrm{ha}^{-1}$ de massa seca de $C$. juncea, sob as mesmas condições relacionadas a tratos culturais. No entanto, a pesquisa foi realizada no período chuvoso (semeadura em novembro). Outra característica que

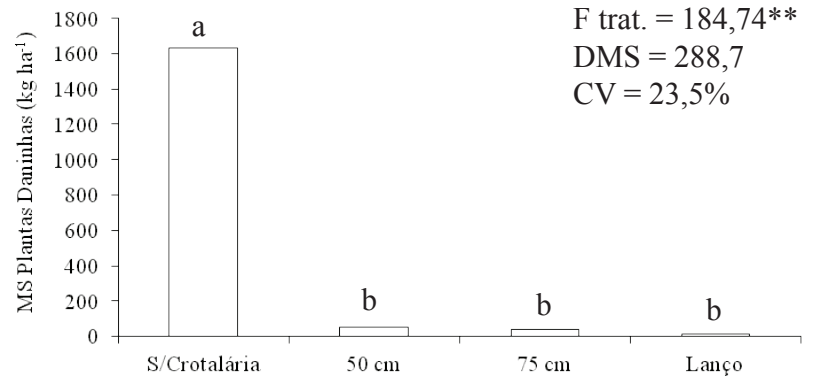

Figura 4. Acúmulo de massa seca $\left(\mathrm{kg} \mathrm{ha}^{-1}\right)$ de plantas daninhas no cultivo de Crotalaria juncea submetida a diferentes métodos de semeadura, no momento da colheita (200 DAS) (Ipameri, GO, 2008).

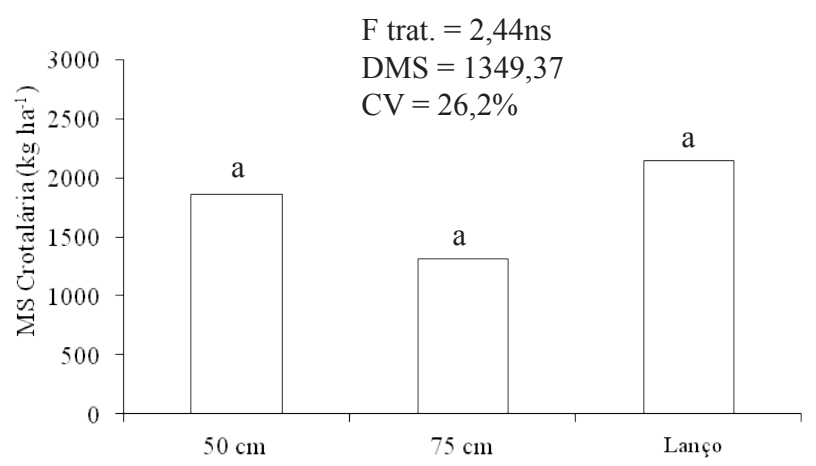

Figura 5. Acúmulo de massa seca de Crotalaria juncea $\left(\mathrm{kg} \mathrm{ha}^{-1}\right)$ submetida a diferentes métodos de semeadura, aos 100 dias após a semeadura (Ipameri, GO, 2008).

fez com que houvesse menor acúmulo de massa seca pelas plantas está relacionada ao fotoperíodo, uma vez que a espécie é "planta de dias curtos" (Amabile et al. 2000), acarretando o florescimento antecipado das plantas e diminuição do seu crescimento, e reduzindo, consequentemente, o acúmulo de massa seca.

Os patamares de produtividade de sementes alcançados na pesquisa (Figura 6) são inferiores ao potencial produtivo da espécie, quando comparados aos resultados obtidos por outros pesquisadores. Bulisani et al. (1980), na região de Campinas (SP), adotando o cultivo na mesma época em que foi conduzida esta pesquisa, nos espaçamentos entre linhas de $30 \mathrm{~cm}, 60 \mathrm{~cm}, 90 \mathrm{~cm}$, obtiveram produtividade de $526 \mathrm{~kg} \mathrm{ha}^{-1}, 336 \mathrm{~kg} \mathrm{ha}^{-1}$ e $291 \mathrm{~kg} \mathrm{ha}^{-1}$, respectivamente. Lovadini et al. (1970), avaliando o potencial produtivo da crotalária, em Campinas (SP), em diferentes épocas de semeadura (novembro, dezembro, janeiro, fevereiro, março e abril), obtiveram maiores produtividades de sementes, quando o cultivo ocorreu 


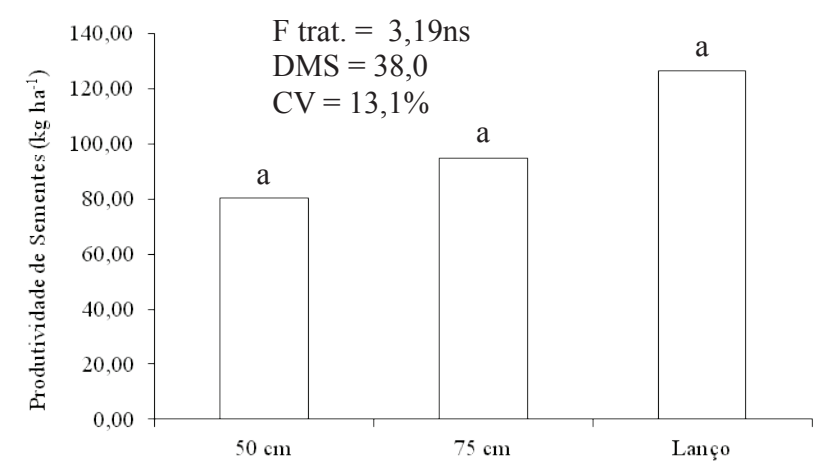

Figura 6. Produtividade de sementes de Crotalaria juncea, cultivada sob diferentes métodos de semeadura (Ipameri, GO, 2008).

no início da estação chuvosa. Quando comparada à produtividade obtida para a mesma época de condução desta pesquisa, verificou-se maior produtividade de sementes. Especula-se que a fertilidade natural dos solos do Cerrado possa ter influenciado diretamente este parâmetro.

Ainda por meio da Figura 6, foi possível constatar que houve semelhança na produtividade, quando comparada aos diferentes métodos de semeadura. Isto evidencia a necessidade de cultivo da espécie sob tratos culturais, como adubação e manejo de pragas e doenças.

$\mathrm{Na}$ condução da pesquisa, foram constatadas sérias infestações de oídio (Erysiphe cichoraceum), nas folhas das plantas, iniciando-se a partir do pré-florescimento das mesmas. Houve, também, infestação de Utetheisa ornatrix, uma espécie de mariposa que ovoposita nas vagens das plantas, cujas lagartas, após a eclosão dos ovos, se alimentam das sementes em formação, destruindo-as. Burle et al. (2006) já mencionaram a necessidade de manejo de algumas destas pragas. Pode-se afirmar que, para estabelecer um programa de produção de sementes de $C$. juncea, torna-se necessário estudo relacionado ao manejo de pragas e doenças, visando a suprir a demanda do setor produtivo.

\section{CONCLUSÕES}

1. O cultivo de Crotalaria juncea, independentemente da disposição de semeadura utilizada, suprimiu o desenvolvimento da comunidade de plantas daninhas.

2. A produção de sementes de Crotalaria juncea não sofreu interferências das formas de distribuição de plantas.

\section{REFERÊNCIAS}

AGUIAR, R. A. et al. Análise econômica de diferentes práticas culturais na cultura do milho (Zea mays L.). Pesquisa Agropecuária Tropical, Goiânia, v. 38, n. 4, p. 241-248, 2008.

AMABILE, R. F.; FANCELLI, A. L.; CARVALHO, A. M. Comportamento de espécies de adubos verdes em diferentes épocas de semeadura e espaçamentos na região dos Cerrados. Pesquisa Agropecuária Brasileira, Brasília, DF, v. 35, n. 1, p. 47-54, 2000.

BULISANI, E. A. et al. Época e espaçamento de semeadura em Crotalaria juncea L. Bragantia, Campinas, v. 39, n. 16, p. 237-240, 1980.

BURLE, M. L. et al. Caracterização das espécies de adubo verde. In: CARVALHO, A. M.; AMABILE, R. F. Cerrado: adubação verde. Planaltina: Embrapa Cerrados, 2006. p. 75-80.

CAVA, M. G. B. et al. Adubos verdes para a renovação de canaviais no sudeste goiano. In: CONGRESSO INTERNACIONAL DE TECNOLOGIA NA CADEIA PRODUTIVA DA CANA, 2., 2008, Uberaba. Anais... Uberaba: FAZU, 2008. 1 CD-ROM.

DOURADO, M. C.; SILVA, T. R. B.; BOLONHEZI, A. C. Matéria seca e produção de grãos de Crotalaria juncea $\mathrm{L}$. submetida a poda e adubação fosfatada. Scientia Agricola, Piracicaba, v. 58, n. 2, p. 287-293, 2001.

ERASMO, E. A. L. et al. Potencial de espécies utilizadas como adubo verde no manejo integrado de plantas daninhas. Planta Daninha, Viçosa, v. 22, n. 3, p. 337 342, 2004.

FAVERO, C. et al. Modificação na população de plantas espontâneas na presença de adubos verdes. Pesquisa Agropecuária Brasileira, Brasília, DF, v. 36, n. 11, p. 13551362, 2001.

LOVADINI, L. A. C.; SALGADO, A. L. B.; MIYAZAKA, $S$. Efeito da época de plantio e da poda na produção de massa verde e sementes de Crotalaria juncea L. Bragantia, Campinas, v. 29, n. 1, p. 25-29, 1970.

MONQUEIRO, P. A. et al. Efeito de adubos verdes na supressão de espécies de plantas daninhas. Planta Daninha, Viçosa, v. 27, n. 1, p. 85-95, 2009.

SEVERINO, F. J.; CHRISTOFFOLETI, P. J. Banco de sementes de plantas daninhas em solo cultivado com adubos verdes. Bragantia, Campinas, v. 60, n. 3, p. 201204, 2001. 
SODRÉ FILHO, J. et al. Fitomassa e cobertura do solo de culturas de sucessão ao milho na região do Cerrado. Pesquisa Agropecuária Brasileira, Brasília, DF, v. 39, n. 4, p. 327-334, 2004.

SOUZA, J. B.; PIRES, F. R. Adubação verde e rotação de culturas. Viçosa: UFV, 2002. (Cadernos didáticos, 96).
TEIXEIRA, C. M.; ARAÚJO, J. B. S.; CARVALHO, G. J. Potencial alelopático de plantas de cobertura no controle de picão-preto (Bidens pilosa L.). Ciência e Agrotecnologia, Lavras, v. 28, n. 3, p. 691-695, 2004. 